\title{
Anticancer Drug Combinations, A Big Momentum is Needed
}

\author{
Lu DY ${ }^{1,2 *}$, Chen EH², Ding $\mathrm{J}^{2}, \mathrm{Xu} \mathrm{B}^{2}$ and Lu TR ${ }^{3}$
}

${ }^{1}$ School of Life Sciences, Shanghai University, Shanghai 200444, PR China

${ }^{2}$ Shanghai Institute of Materia Medica, Chinese Academy of Sciences, Shanghai 201203, PR China

${ }^{3}$ College of Science, Shanghai University, Shanghai 200444, PR China

\begin{abstract}
Most cancer therapies are seldom effective by using one anticancer drug owing to refractory and resistance property of cancer tissues caused by multiple genetic alterations and molecular abnormalities. Despite great popularity of anticancer drug combination utilizations, the hidden rules behind scenarios emerge in new era of anticancer therapy. Most importantly, anticancer drug cocktails need to transform from empirical to science-guided enterprises. This editorial offers the background knowledge of drug combination therapy across the history. Possible future landscapes and drawbacks of current cancer drug combinative therapy are addressed and speculated.
\end{abstract}

Keywords: Drug combination; Drug resistance; Neoplasm metastasis; Biotherapy; Cytotoxic anticancer drugs; Cancer stem cell; Personalized cancer therapy

\section{Introduction}

Cancer is a common disease that claims life about 7-10 million people annually in the world. As a result, cancer remains to be a great medical challenge worldwide [1-3]. Many efforts can impact the overall therapeutic efficacies and outcomes of cancer treatments. One of these efforts is anticancer drug combinations. Long before, it was widely accepted that anticancer drug cocktail instead single drugs usually improved the therapeutic efficacies greatly [4-10]. Despite its great popularity and as a modern cliché, how to prescribe the recipe of anticancer drug cocktails are emerging problems. Since few anticancer drug combinations modular have been subjected for mechanism investigations and highlighted into scientific principle discoveries, anticancer drug cocktail designs need to transform from empirical decision into science-guided modern predictive systems. Only by science-guided strategy, cancer drug combinative therapy might make great difference. The scenarios of our understandings of anticancer drug combinations are addressed and highlighted in this perspective.

\section{Limitations of single anticancer drug therapies}

Weaknesses and limitations of single anticancer drug therapies are higher diversity of tumor malignancies and incomplete killing all cancer cells owing to the toxicities of anticancer drugs. Many diversity phases of pathogenesis play pivotal roles for resistance of drugs and cancer patient's deaths. Owing to the toxicity of a lot of antineoplastic drugs to human bodies, the human tolerate dosage of anticancer drugs must not be ranged at the high dosage for single anticancer drug therapies, which results in incompletely killing of all tumor cells and inductions of multidrug resistance (MDR) tumor cells after several cycles of tumor proliferations and survivals at normal drug administration doses. Anticancer drugs can be divided into two categories-cytotoxic anticancer drugs and cytostatic (targeted) anticancer drugs [11]. Since the cytotoxic antineoplastic drugs targeting at inhibiting tumor proliferations are commonly high toxicity and wide-spectra effectiveness, they also damage normal human cells at the same times of killing cancer cells. Thus the dosages of single antineoplastic drug in human therapy cannot be too high to be tolerated by humans. At the end, small proportions of cancer cells survive after one or two regimes of cytotoxic anticancer drug chemotherapy. These tumor cells will regrow to large tumor volumes again and multidrug resistance (MDR) to cytotoxic anticancer drugs often occurs in regrowed cancer cells. Yet cytotoxic anticancer drugs are good partner with most other types of anticancer (targeted agents), biotherapy or assistant therapies.

\section{Introductions of general ideas and different drug combination modular}

Previously, combination utilizations of cytotoxic anticancer chemicals with biotherapy or other therapeutic means are good strategies for cancer treatments [8-10]. Many similar examples are given later and will be discussed one by one. Several modular of anticancer drug combination systems are temporarily categorized as followings;

1. Combine anticancer drugs of different targeting and mechanisms of action;

2. Reduce the toxicities of cytotoxic anticancer drugs by other drugs;

3. Combinations of chemical cytotoxic anticancer drugs or radiotherapy with different types of biotherapeutic agents;

4. Combine cytotoxic anticancer drugs with cytostastic (targeted) anticancer drugs;

5. Combine cytotoxic anticancer drugs with less toxic assistant or adjuvant agents;

6. Combine anticancer drugs with drugs for drug resistance improvements;

7. Combine anticancer drugs targeting primary tumors with antimetastatic drugs;

8. Combine anticancer drugs with cancer stem cell modulators or inhibitors;

9. Combine anticancer drugs by individualized or personalized evaluation and predictions of drug toxicity and responses etc.

*Corresponding author: Lu DY, School of Life Sciences, Shanghai University, Shanghai, China, Tel: Tel: +86 21 66163545; Fax: +821 66132177; E-mail: ludayong@sh163.net

Received August 10, 2015; Accepted August 15, 2015; Published August 17 , 2015

Citation: Lu DY, Chen EH, Ding J, Xu B, Lu TR (2015) Anticancer Drug Combinations, ABig Momentum is Needed. Metabolomics 5: e139doi:10.4172/21530769.1000e139

Copyright: (c) 2015 Lu DY, et al. This is an open-access article distributed under the terms of the Creative Commons Attribution License, which permits unrestricted use, distribution, and reproduction in any medium, provided the original author and source are credited. 


\section{Different modular of anticancer drug combination strategies}

Since no central dogma of anticancer drug combinations suitable for all cancer patients has been found, some propositions should be made first. It is proposed herein whether it is optimal for utilizations of different categories of inhibitors as drug combination principles for cancer therapeutics. Furthermore, a great number of cellular genotypic or phenotypic changes of human tumor hallmarks can be individually targeted by relevant anticancer drugs [8]. As a result, anticancer drugs targeting different cancer molecules, phenotypes and pathways might cooperate with each other to kill or inhibit cancer growths more effectively.

\section{Reduce the toxicities of cytotoxic anticancer drugs by other types of drugs}

Reducing the toxicities of cytotoxic anticancer drugs by other drugs is a common modular of drug combinations. Since most cytotoxic anticancer drugs are very toxic, some types of toxicities for cytotoxic anticancer drugs are difficult to be tolerated at high doses in normal humans. More structural revisions by medicinal chemistry comparisons or even counteract by other types of drugs may enjoy great successes. Best example is the combinations of anthrocyclines such as doxorubicin with bisdioxopiperazine compounds (Biz) such as razoxane [12-15] and probimane [16-19]. More interestingly, doxorubicin and Biz compounds could cooperate one and another in combating with drug-resistance and neoplasm metastasis $[12,13,16,17]$.

\section{Cytotoxic drugs and biotherapy combinations}

One of these modular and paradigms is possibly the combination of cytotoxic chemicals with biotherapies [8-10]. Cytotoxic anticancer drugs are wide-spectra cancer inhibitors that are active against almost all cancer categories. But commonly, no dosage of $100 \%$ cancer inhibition can be applied to cancer patients. If cytotoxic anticancer chemical drugs only kill $70 \%$ to $95 \%$ of tumor cells, some highly specific biotherapies are proposed to kill the rest of tumor cells with no marked toxicities [8-10]. The best example supporting this paradigm is to combine cytotoxic anticancer chemicals with mono-clonal or polyclonal antibodies [20-28]. The obvious combinative therapeutic efficacies are frequently reported among international journals.

\section{Combine cytotoxic anticancer drugs with assistant agents}

The causes for the death of cancer patients can be multi-factorial in clinics. Apart from direct causes of tumor progressions and metastases by all genetic possibilities, other clinical complications or psychiatry factors will more or less speed up the deaths of cancer patients. So many assistant therapies will give the cancer patients who show some clinical complications or psychiatry abnormal conditions [29-42]. Next to cancer metastasis, the second deadly pathological feature of cancer patients is the venous thromboembolism [29]. For example, cancer patients with venous thromboembolism symptoms have the higher possibilities and rates of cancer patient deaths and been hypothesized to be counteracted with assistant therapy of anticoagulants (AC) and/ or fibrinolytic agents (FA) such as warfarin, heparin or oxalysine. The other important problem is which categories of solid cancer are suitable for prophylaxis anti-thrombosis therapy. Only half of patients are statistically significant to improve survivals by anti-thrombosis therapy. Approximately $1 / 3$ of cancer patients show survival benefits by AC, while the other $1 / 3$ cancer patients can be improved by FA [ 30 32]. More recently, lung cancer patients' survival has been reported to improve a great deal by giving anti-thrombosis therapy $[32,35]$. A lot of people believe that cancer is an incurable disease. Some of them frighten to death after hearing they contract advanced cancers. Their mental strengths of these cancer patients collapse afterward of hearing truth. Generally, the fear among cancer patients will speed up the patient's deaths. It has been hypothesized whether antidepressants can be assistant therapies for patients with psychiatry problems $[8,41,42]$. This is a rarely noticed therapeutic option and subjected to less systemized investigations. But it may be a unique therapeutic target if we can revisit this approach afterwards. As assistant treatment paradigms for cancer patients have been proposed to mainly prolong patient's survivals in wide ranges of cancer patients and promote the quality of patient's life. Assistant therapies, however, need to combine use with anticancer or antimetastatic drugs. Or the therapeutic efficacies of many assistant therapies should be greatly undermined, or even useless in clinical trials.

Combine use of drugs both antiproliferative drugs (primary tumor) and antimetastatic drugs (remote disseminations)

A lot of cancer patients die of cancer metastasis ( $90 \%$ of cancer deaths). It means current antimetastasis therapies are unsatisfactory and imperfect due to the complicate processes of neoplasm metastasis [43-51]. Despite some achievements in metastatic therapeutics, cancer metastasis treatments often fail in clinical trials [50,51]. Apart from manufacturing high effective and specificity anticancer or antimetastatic drugs [46-51], combinative utilizations of both antiproliferative drugs (primary tumor) and antimetastatic drugs is supposed to be a useful paradigm for survival elongations of many advanced (late-staged) cancer patients. Theoretically, good antimetastatic therapy should not be uniformed and must be tailored for different pathogenic stages [50,51].

\section{Combine cytotoxic drugs with cytotoxic drugs}

Anticancer drugs (chemical agents) are generally divided into two distinct categories; cytotoxic drugs or cytostatic drugs [11]. As anticancer drugs are great in number 84 anticancer drugs licensed in US and 178 drugs licensed in the world in 2013) [52,53], most of anticancer drugs are cytotoxic and cytostastic drugs. Thus combining cytotoxic drugs with cytotoxic drugs and cytotoxic drugs with cytostatic drugs is the major types of drug combinations in clinical trials. Since there are diversity in therapeutic efficacies, toxicities, mechanisms of action and therapeutic pathways by different anticancer drugs in individual cancer patients, may some other predictive or selective systems (such as drug sensitivity testing etc) be borrowed? [54-56].

\section{Combination of anticancer drugs and cancer stem cell (CSC) modulators or inhibitors}

CSCs are the main components of cancer therapeutic resistance, neoplasm metastasis and treatment relapse [57-61]. Many CSC modulators or inhibitors have been discovered and developed within the past several decades. CSC modulator or inhibitor combinations with standard anticancer drugs have been widely reported (Table 1). In spite of this popularity, less successful evidence has been found in clinics. Many factors behind scenes need to be uncovered. The CSC modulators or inhibitors in this stage are imperfect owing to its moderate toxicities and marginal therapeutic benefits in clinics. Moreover, CSC only consists of less than $10 \%$ of tumor volumes [45], can this small proportion of CSCs play pivotal role for neoplasm metastasis and therapeutic relapse? Before becoming a major therapeutic paradigm, basic understanding the pathogenesis and therapeutics of CSC is indispensable. 


\begin{tabular}{|l|l|l|}
\hline $\begin{array}{l}\text { Stemness } \\
\text { modulator drugs }\end{array}$ & Standard anticancer drugs & Cancer types \\
\hline Salinomycin & $\begin{array}{l}\text { Gemcitabine } \\
\text { Octreotide modified paclitaxel } \\
\text { Etoposide } \\
\text { Doxorubicin }\end{array}$ & $\begin{array}{l}\text { Pancreatic } \\
\text { Breast } \\
\text { Hepatic } \\
\text { Uterine, sarcoma, breast }\end{array}$ \\
\hline SANT-1 & SAHA & Pancreatic \\
\hline GSI-XII & $\begin{array}{l}\text { Bortezomib } \\
\text { ABT-737 }\end{array}$ & $\begin{array}{l}\text { Multiple myeloma } \\
\text { Multiple myeloma }\end{array}$ \\
\hline Curcumin & $\begin{array}{l}\text { Dasatinib } \\
\text { Gemcitabine } \\
\text { Gemcitabine } \\
\text { Placlitaxel } \\
\text { Tumor necrosis factor (TNF) } \\
\text { TNF-related apoptosis inducing } \\
\text { ligand } \\
\text { 5-FU plus oxaliplatin }\end{array}$ & $\begin{array}{l}\text { Colon } \\
\text { Pancreatic } \\
\text { Bladder }\end{array}$ \\
\hline ER-400583-00 & Radiation & Colon \\
\hline $\begin{array}{l}\text { VEGFR2 targeting } \\
\text { antibody }\end{array}$ & Cyclophosphamide & Gliomas \\
\hline
\end{tabular}

Table 1: Examples of combination therapy with stemness modulator drugs and standard anticancer drugs.

\section{Present customs of anticancer drug discovery, development, and/or licensing}

Discovery and developments of more effective anticancer drugs are indispensable parts of drug manufactures and advancements of cancer therapies. Since cancer is different diseases with pathogenesis characteristics of unlimited growth and metastasis, different categories of anticancer drugs might be sensitive to different tumor types and pathologic stages. Tendency of modern anticancer drug developments is to screen for diversified tumor models, drug molecular targets and pathways. $[52,53,62,63]$ The quality of drug responses and toxicities evaluations is almost affected by $50 \%$ owing to the diversity of tumor models. High expenditures of anticancer drug development are often encountered. Averagely, 1.0-1.8 billion UDS must be covered for licensing a single anticancer drug in US $[52,62]$. From this scenario, only a few of big pharmaceutical companies from wealthy countries such as Swiss, UK, Germany and US etc can offer anticancer drug licensing worldwide. Soaring cancer therapeutic fee will be paid for clinical chemo- or biotherapies using patent-protected anticancer drugs. Rethink of anticancer evaluation and development systems has been discussed frequently [63]. Any new movements of anticancer drug developments may impact the cancer therapeutic routines and provide fertile soils for the growth of personalized cancer therapy and drug combination modular [54-56]. Further information and future perspective will be given in the followings.

\section{Discussion}

Since huge possibilities of drug combination protocols can be assembled in clinics owing to large numbers of anticancer drugs being licensed worldwide (178 anticancer drugs worldwide in 2013) [53], it needs great deals of efforts and moneys to complement and optimally designing. Mounting experimental data and clinical evidence suggest that it is a good way for using drug combination in combating tumor growth and metastasis simultaneously. However, the toxicities of drug combination are parallel by the increase of drug numbers. Drug sensitivity tests, cancer biomarker detecting and pharmacogenetics are designed to select effective and optimal numbers of anticancer drugs and discard ineffective drugs for economic or therapeutic reasons [5456] and pharmaceutical considerations, such as liposome-entrapped drugs or nano-drugs [64-66]. They can make a new balance between drug activity and toxicity. However, new technologies do not always mean good things. These new options (modern techniques) are too early to be superstitious. For example, nano-anticancer drugs are not always affinity to tumor tissues and less toxicities to humans. The toxicities to human immune cells and systems are increased by nanoanticancer drug treatments. New balance between drug efficacies and toxicities might happen [64-66].

\section{Conclusion}

In future, we must pay more attentions on the breakthrough of drug combinational rule discoveries and systemized. Only by these discoveries and systemizations, therapeutic efficacies for cancer treatments can be well improved and developed for a long run. Since there is no central dogma available for clinical anticancer drug combinations of repeatable experimental protocols and hospital routines, we hope this article can serve as a gateway between past and future cancer chemotherapy norm and help to build a bridge to embrace better therapeutic options.

\section{Acknowledgements}

This work was funded by Shanghai Science and Technology Foundation of High Educations 97A49.

\section{References}

1. Siegel RL, Miller KD, Jemal A (2015) Cancer stastistics. CA: A Cancer J Clin 65: 5-29

2. Ali I, Rahis-ud-din, Saleem K, Aboul-Enein HY, Rather A (2011) Social aspects of cancer genesis. Cancer Therapy 8: 6-14.

3. Ali I, Wani WA, Saleem K (2011) Cancer scenario in India with future perspectives. Cancer Therapy 8: 56

4. Tipping AJ, Melo JV (2003) Imatinib mesylate in combination with other chemotherapeutic drugs: In vitro studies. Semin Hematol 40: 83-91.

5. Druker B (2003) Imatinib alone and in combination for chronic myeloid leukemia. Semin Hematol 40: 50-58.

6. Strausberg RL, Simpson AJG, Old LJ, Riggins GJ (2004) Oncogenomics and the development of new cancer therapies. Nature 429: 469-474.

7. Siegel DS, Richardson P, Dimopoulos M, Moreau P, Mitsiades C, et al. (2014) Vorinostat in combination with lenalidomide and dexamethasone in patients with relapsed or refractory multiple myeloma. Blood Cancer J 4: e182.

8. Lu DY, Lu TR, Chen XL, Ding J (2012) Individualized cancer chemotherapy Hypotheses in Clinical Medicine. Nova Science Publisher, US.

9. Lu DY, Lu TR, Wu HY (2013) Combination chemical agents with biological means in cancer therapy. Res Rev in BioSci 7: 153-155.

10. Lu DY, Lu TR, Cao S (2013) Drug combinations in cancer treatment. Clin Exp Pharmacol 3: 134

11. Millar AW, Lynch KP (2003) Rethinking clinical trials for cytostatic drugs. Nat Rev Cancer 3: 540-545.

12. Herman EH, Witiak DT, Hellmann K, Waradek VS (1982) Biological Properties of ICRF-159 and related Bis (dioxopiperazine) compounds. Adv Pharmacol Chemother 19: 249-90

13. Lu DY, Lu TR (2010) Anticancer activities and mechanisms of bisdioxopiperazine compounds probimane and MST-16. Anticancer Agents Med Chem 10: 78-91.

14. Herman EH, Ferrans VJ, Bhat HB, Witiak DT (1987) Reduction of chronic doxorubicin cardiotoxicity in beagle dogs by bis-morpholinomethyl derivative of razoxane (ICRF-159). Cancer Chemother Pharmacol 19: 277-281.

15. Martin E, Thougaard AV, Grauslund M, Jensen PB, Bjorkling F, et al. (2009) Evaluation of the topoisomerase II-inactive bisdioxopiperazine ICRF-161 as a protectant against doxorubicin-induced cardiomyopathy. Toxicol 255: 72-79.

16. Zhang Y, Ye QX, Liu J, Zhang ZY, Zhang TM (1994) Synergistic effective of probimane on anticancer cytotoxicity of doxorubicin in vitro. Acta Pharmaco Sin 15: $56-59$

17. Lu DY, Xu B, Ding J (2004) Antitumor effects of two bisdioxopiperazines against two experimental lung cancer models in vivo. BMC Pharmacol 4: 32. 
Citation: Lu DY, Chen EH, Ding J, Xu B, Lu TR (2015) Anticancer Drug Combinations, A Big Momentum is Needed. Metabolomics 5: e139doi:10.4172/2153-0769.1000e139

Page 4 of 4

18. Vuong MC, Hasegawa LS, Eastmond DA (2013) A comparative study of the cytotoxic and genotoxic effects of ICRF-154 and bimolane, two catalytic inhibitors of topoisomerase II. Mutat Res 750: 63-71.

19. Barry E, Vrooman LM, Dahlberg SE, Neuberg DS, Asselin BL, et al. (2008) Absence of secondary malignant neoplasms in children with high-risk acute lymphoblastic leukemia treated with dexrazoxane. J Clinical Oncology 26: 1106-1111.

20. Lechleider RJ, Kaminskas E, Jiang XP (2008) Ixabepilone in combination with capecitabine and as monotherapy for treatment of advanced breast cancer refractory to previous chemotherapies. Clin Cancer Res 14: 4378-4384.

21. Gillespie DL, Whang K, Ragel BT, Flynn JR, Kelly DA, et al. (2007) Silencing of hypoxia inducible factor- $1 \alpha$ by RNA interference attenuates human glioma cell growth in vivo. Clin Cancer Res 13: 2441-2448.

22. Geyer CE, Forster J, Lindqyuist D (2006) Lapatinib plus capecitabine for HER2positive advanced breast cancer. N Engl J Med 355: 2733-2743.

23. Vermorken JB, Mesia R, Rivera F (2008) Platinum-based chemotherapy plus cetuximab in head and neck cancer. N Engl J Med 359: 1116-27.

24. Ball ED, Broom HE (2010) Monoclonal antibodies in the treatment of hematologic malignancy. Best Pract Res Clin Haematol 23: 403-416.

25. Younes A, Barttett NL, Leonard JP, Kennedy DA, Lynch CM, et al. (2010) Brentuximab vedotin (SGM-35) for relapsed CD30-positive lymphomas. N Engl J Med 363: 1812-1821

26. Miller K, Wang M, Gralow J (2007) Paclitaxel plus bevacizumab versus paclitaxel alone for metastatic breast cancer. N Engl J Med 357: 2666-2676.

27. Tol J, Koopman M, Cats A (2009) Chemotherapy, bevacizumab, and cetuximab in metastatic colorectal cancer. N Engl J Med 360: 563-572.

28. Couzin-Frankel J (2013) Cancer immunotherapy. Science 342: 1432-1433.

29. Mandala M, Ferretti G, Cremonesi M, Cazzaniga M, Curigliano G, et al. (2003) Venous thromboembolism and cancer: new issues for an old topic. Critical Rev in Oncology/Hematology 48: 65-80

30. Dvorak HF, Senger DR, Dvorak AM (1983) Fibrin as a component of the tumor stroma: origins and biological significance. Cancer Metastasis Rev 2: 41-73.

31. Costantini V, Zacharski LR (1992) The role of fibrin in tumor metastasis. Cancer Metastasis Rev 11: 283-290.

32. Lu DY, Chen XL, Ding J (2007) Treatment of solid tumors and metastases by fibrinogen-targeted anticancer drug therapy. Med Hypotheses 68: 188-193.

33. Lu DY, Chi J, Lin LP, Huang M, Xu B, et al. (2004) Effect of anticancer drugs on the binding of ${ }^{125}$-fibrinogen to two leukemia cell lines in vitro. $\mathrm{J}$ Int Med Res 32: 488-491

34. Lu DY, Lu TR, Che JY, Wu HY (2014) Old theories revisited on cancer assistant therapy. Int J Med Health Science Res 1: 50-57.

35. Bobek V (2012) Anticoagulant and fibrinolytic drugs possible agents in treatment of lung cancer? Anticancer Agents Med Chem 12: 580-588.

36. Rothwell P, Fowkes FG, Belch JF, Ogawa H, Warlow CP, et al. (2011) Effect of daily aspirin on long-term risk of death due to cancer: analysis of individual patient data from randomized trials. Lancet 377 : 31-41.

37. Grint T, Riley AM, Mills SJ, Potter BVL, Safrany ST (2012) Fibrinogen a possible extracellular target for inosital phosphates. Messenger 1: 160-166.

38. Lu DY, Lu TR, Chen EH, Ding J, Xu B (2015) Tumor fibrin/fibrinogen matrix as a unique therapeutic target for pulmonary cancer growth and metastases. Clin Res Pulmonology 3: 1027.

39. Che DH, Cao JY, Shang IH, Man YC, Yu Y (2013) The efficacy and safety of low-molecular-weight-heparin use for cancer treatment; a meta-analysis. Eur J Internal Med 24: 433-439.

40. Uppal S, Hernandez E, Dutta M, Dandolu V, Rose S, et al. (2012) Prolonged postoperative venous thrombo-embolism prophylaxis is cost-effective in advanced ovarian cancer patients. Gynecol Oncol 127: 631-637.

41. Lieb J (2007) Antidepressants, prostaglandins and the prevention and treatment of cancer. Med Hypotheses 69: 684-689.

42. Lu DY, Lu TR (2008) Antidepressants can be only used as assistant therapy in cancer treatment. Med Hypotheses 70: 204-205.
43. Talmadge JE, Fidler IJ (2010) The biology of cancer metastasis: historical perspective. Cancer Res 70: 5649-5669.

44. Mina LA, Sledge GW (2011) Rethinking the metastatic cascade as a therapeutic target. Nat Rev Clin Oncol 8: 325-332.

45. Chaffer CL, Weinberg RA (2011) A perspective on cancer cell metastasis Science 331: 1559-1564

46. Lu DY, Lu TR, Cao S (2012) Cancer metastases and clinical therapies. Cell \& Developmental Biology 1: e110.

47. Valastyan S, Weinberg RA (2011) Tumor metastasis: molecular insights and evolving paradigms. Cell 147: 275-292.

48. Lu DY, Lu TR, Wu HY (2011) Antimetastatic therapy targeting aberrant sialylation profiles in cancer cells. Drug Ther Studies 1: e12.

49. Lu DY, Lu TR, Wu HY (2012) Development of antimetastatic drugs by targeting tumor sialic acids. Scie Pharm 80: 497-508.

50. Lu DY, Lu TR, Wu HY (2013) New insights into individualized antimetastatic therapy. Adv Tech Bio Med 1: 106.

51. Lu DY, Lu TR, Wu HY, Cao S (2013) Cancer metastases treatments. Current Drug Therapy 8: 24-29.

52. Gupta SC, Sung B, Prasad S, Aggarwal BB (2013) Cancer drug discovery by repurposing: teaching new tricks to old dogs. Trends Pharmacol Sci 34: 507517

53. Ali I, Haque A, Wani WA, Saleem K, Al za'zbi M (2013) Analyses of anticance drugs by capillary electrophoresis; a review. Biomed Chromatogr 27: 12961311.

54. Lu DY, Chen XL, Ding J (2006) Individualized cancer chemotherapy integrating drug sensitivity tests, pathological profile analysis and computational coordination - an effective strategy to improve clinical treatment. Med Hypotheses 66: 45-51.

55. Lu DY (2014) Personalized cancer chemotherapy, an effective way for enhancing outcomes in clinics. Woodhead Publishing, Elsevier, UK.

56. Lu DY, Lu TR, Che JY, Wu HY (2014) Individualized cancer therapy. IPP 2 458-469.

57. Yakisich JS (2012) Challenges and limitations of targeting cancer stem cells and/or the tumour microenvironment. Drug Therapy Study 2: e10.

58. Park TS, Donnenberg VS, Donnenberg AD, Zambidis ET, Zimmerlin L (2014) Dynamic interactions between cancer stem cells and their stromal partners. Current Pathobiol Reports 2: 41-52.

59. Visvader JE, Lindeman GJ (2008) Cancer stem cells in solid tumours: accumulating evidence and unresolved questions. Nat Rev Cancer 8: 755-768.

60. Magee JA, Piskounova E, Morrison SJ (2012) Cancer stem cells: impact heterogeneity, and uncertainty. Cancer Res 21: 283-96

61. Li Y, Laterra J (2012) Cancer stem cells: distinct entities or dynamically regulated phenotypes? Cancer Res 72: 576-580

62. Ruggeri BA, Camp F, Miknyoczki S (2014) Animal models of disease: Preclinical animal models of cancer and their applications and utility in drug discovery. Biochem Pharmacol 87: 150-161.

63. Lu DY, Chen EH, Lu TR (2015) Anticancer Drug Development, a Matter of Money or a Matter of Idea? Metabolomics 5: e134.

64. Kizitepe T, Ashley JD, Stefanick JF, Qi YM, Alves NJ, et al. (2012) Rationally engineered nanopartcles target multiple myeloma cells, overcome celladhesion-mediated drug resistance and show enhanced efficacy in vivo. Blood Cancer J 2: e64

65. Ali I (2011) Nano anti-cancer drugs: Pros and cons and future perspectives Curr Cancer Drug Targets 11: 131-134.

66. Ali I, Salim RK, Rather MA, Haque A (2011) Advances in nano drugs for cance chemotherapy. Curr Cancer Drug Targets 11: 135-146. 